Дикая Л. А., Обухова Ю. В., Егорова В. А., Егоров И. Н.

ОСОБЕННОСТИ ВЗАИМОСВЯЗЕЙ ЭМОЦИОНАЛЬНОГО ИНТЕЛЛЕКТА И ЛИЧНОСТНЫХ ЧЕРТ...

РосСиЙский психологИЧЕский ЖУРнАл, 2020, Т. 17, № 4, 34-48. doi: 10.21702/rpj.2020.4.3

психология личности

УДК 159.9.072.432 doi: $10.21702 /$ rpj.2020.4.3

Оригинальная научная статья

\title{
Особенности взаимосвязей эмоционального интеллекта и личностных черт у социально активных студентов
}

\author{
АюАмила А. Аикая*, Юлия В. Обухова, Валерия А. Егорова, Илья Н. Егоров \\ Южный фелеральный университет, г. Ростов-на-Аону, Российская Фелерация \\ *E-mail: dikaya@sfedu.ru \\ ORCID ID: https://orcid.org/0000-0002-1000-772X, https://orcid.org/0000-0002-8976-4650, \\ https://orcid.org/0000-0001-6159-7072, https://orcid.org/0000-0002-1645-7983
}

\begin{abstract}
Аннотация
Введение. Новизна исслеАования заключается в изучении взаимосвязи эмоционального интел^екта и личностных черт у социально активных стуАентов нового поколения, а также в глубине изучения взаимосвязи, которая рассматривается не только на уровне общих и интегральных показателей, но и на уровне их составляющих.

Методы. В исследовании приняли участие 132 студента Южного фелерерального университета в возрасте от 17 Ао 25 ^ет, из них 80 женщин и 52 мужчины. Все респонденты являются преАставителями социально активной молодежи, принимают активное участие в профрессиональных и творческих конкурсах, социальных проектах и характеризуют свой уровень социальной активности Как высокий или выше среАнего. В ИсслеАОвании использовались: опросник эмоционального интелмекта «ЭмИн» А. В. Аюсина, «Big Five Inventory-2») («Вопросник Большой Пятерки-2») в русской алаптации С. А. Щебетенко. А^я статистической обработки Аанных применялась программа R с использованием непараметрической и параметрической статистики.

Результаты и их обсужаение. У социально активных студентов выявлены общие, характерные Аля всех компонентов, и специфричные, характерные Аля отАельных компонентов эмоционального интелмекта, его взаимосвязи с мичностными чертами. К общим отнесены взаимосвязи мичностных черт «нейротизм» и «тревожносты» со всеми структурными компонентами эмоционального интелмекта. К специфричным отнесены положительные взаимосвязи показате^я «энергичность» с компонентами эмоционального интел^екта, отвечающими за управление эмоциями, и отрицательные взаимосвязи показателя «эмоциональная ^абильность» со структурными компонентами внутриличностного эмоционального интелмекта $(p \leq 0,05)$. Выявлено влияние сочетания нейротизма и Аоброжелательности на уровень общего и межличностного эмоционального интемлекта, а сочетания экстраверсии и нейротизма-на уровень внутриАичностного эмоционального интемлекта.

Заключение. Результаты могут получить применение при разработке рекомендаций по психолого-пеАагогическому сопровожАению студентов с особыми образовательными потребностями в социальной активности, с АиАерской оАаренностью при разработке инАивиАуальных образовательных траекторий учащихся.
\end{abstract}


Дикая Л. А., Обухова Ю. В., Егорова В. А., Егоров И. Н.

ОСОБЕННОСТИ ВЗАИМОСВЯЗЕЙ ЭМОЦИОНАЛЬНОГО ИНТЕЛЛЕКТА И ЛИЧНОСТНЫХ ЧЕРТ...

РосСИЙСКИЙ пСИХОЛОГИЧЕСКИЙ ЖУРнАл, 2020, Т. 17, № 4, 34-48. doi: 10.21702/rpj.2020.4.3

психология личности

\section{КАючевые слова}

эмоциональный интелмект, ^ичностные черты, нейротизм, экстраверсия, Аоброжелательность, открытость опыту, Аобросовестность, социальная активность, стуленты, особые образовательные потребности

\section{Основные положения}

$\checkmark$ высокие показатели экстраверсии как личностной черты социально активных студентов способствуют повышению уровня межличностного эмоционального интел^екта, а низкие показатели нейротизма солействуют развитию внутриличностного эмоционального инте^^екта;

D у социально активных студентов на выраженность общего и межличностного эмоционального интеллекта оказывают влияние сочетание нейротизма и Аоброжелательности, а на выраженность внутриличностного эмоционального интелмекта - сочетание экстраверсии и нейротизма;

$\checkmark$ взаимосвязь показателей нейротизма, экстраверсии и эмоционального интелмекта может послужить основой при разработке технологий психокоррекционного возАействия в работе со студентами с потребностями в социальной активности.

\section{Для цитирования}

Дикая, Л. А., Обухова, Ю. В., Егорова, В. А. и Егоров, И. Н. (2020). Особенности взаимосвязей эмоционального интеллекта и личностных черт у социально активных студентов. Российский психологический журнал, 17(4), 34-48. doi: 10.21702/rpj.2020.4.3

Дата получения рукописи: 23.09.2020

Дата окончания рецензирования: 23.10 .2020

Дата принятия к публикации: 24.10.2020

\section{Введение}

Развитие российского образования в XXI в. невозможно без ответов на предъявляемые ему вызовы общества. Чтобы стать конкурентоспособным и успешным в условиях переизбытка информации и существенно возросшего количества межличностных контактов, современный студент должен быть социально активным, постоянно развивать свои коммуникативные способности и навыки. Большое значение при этом имеет эмоциональный интеллект молодого человека, уровень развития которого способствует адекватному восприятию партнера, эмоциональной саморегуляции, что, в свою очередь, существенно влияет на эффективность его общения.

За последние три десятка лет значительно увеличилось количество научных работ, посвященных исследованию эмоционального интеллекта. Наибольшая часть этих работ направлена на изучение роли эмоционального интеллекта в личностных и профессиональных достижениях молодых людей. Авторами, в частности, выявлена достоверная взаимосвязь высокого уровня эмоционального интеллекта у участников проведенных исследований с готовностью успешно осваивать университетские программы в онлайн-формате (Аленези, 2020), с эмоциональной регуляцией (Megías-Robles et al., 2019), эмоциональной стабильностью (Lyusin \& Mohammed, 2018), с успешным межпрофессиональным общением и лидерскими качествами у студентов (Haight et al., 2017). Также выявлен наиболее высокий 
Дикая Л. А., Обухова Ю. В., Егорова В. А., Егоров И. Н.

ОСОБЕННОСТИ ВЗАИМОСВЯЗЕЙ ЭМОЦИОНАЛЬНОГО ИНТЕЛЛЕКТА И ЛИЧНОСТНЫХ ЧЕРТ...

РосСийский психологИЧЕский ЖУРнАл, 2020, Т. 17, № 4, 34-48. doi: 10.21702/rpj.2020.4.3

психология личности

уровень эмоционального интеллекта в период ранней взрослости, и обоснована его роль для самореализации молодых людей (Обухова, 2013; Обухова и Обухова, 2015). Таким образом, исследователями показана значительная роль эмоционального интеллекта в успешной социальной активности молодежи.

Термин «эмоциональный интеллект» введен в научную психологию в 1990 г. П. Сэловеем и Д. Майером, которые определили его как одну из форм интеллекта, которая отвечает за способность отслеживать и выделять свои и чужие эмоции и использовать данную информацию при формировании плана действий (Salovey \& Mayer, 1990). С того момента концепт эмоционального интеллекта неоднократно пересматривался и менялся. В отечественной психологии наиболее полно определил эмоциональный интеллект Д. В. Люсин. Эмоциональный интеллект, по Д. В. Люсину, - это психологическое образование, формирующееся в ходе жизни человека под влиянием ряда факторов, которые обуславливают его уровень и специфические индивидуальные особенности. Эмоциональный интеллект включает в себя способность к пониманию своих и чужих эмоций и управлению ими (Люсин, 2004).

Вопрос взаимосвязи эмоционального интеллекта и личностных черт привлек активное внимание исследователей лишь во второй декаде XXI в. (Бочкова и Мешкова, 2018; Воробьева, Перков и Щетинина, 2017; Saakyan, 2015; Шипитько, 2019; Atta, Ather, \& Bano, 2013). Безусловно, и до этого периода существовали эмпирические исследования, посвященные данной тематике, но они носили в основном единичный характер (van der Zee, Thijs, \& Schakel, 2002; Avsec, Takšić, \& Mohorić, 2009). В психологической науке по-прежнему эмоциональный интеллект и личностные черты в большинстве случаев исследуются изолированно друг от друга при изучении других психологических характеристик, например, лидерства, настроения и др. (Краснов, 2018; Люсин и Овсянникова, 2015; Белоконь, 2008; Stolarski, Jankowski, Matthews, \& Kawalerczyk, 2016). Именно в рамках исследований, где изучалось влияние эмоционального интеллекта и личностных черт на другие психологические характеристики, были отмечены корреляции между личностными чертами и эмоциональным интеллектом.

В отечественной науке вопрос взаимосвязи эмоционального интеллекта и личностных черт представлен в работе Люсина (2006). Выборка его исследования состояла из студентов в возрасте от 17 до 27 лет. В 20-х гг. XXI в. в условиях цифровизации, снижения доли межличностного общения в студенческой среде, сложившейся на данный момент эпидемиологической ситуации и ожидаемого увеличения объема дистанционного обучения, пропорционально возрастающей его доли в рамках смешанной модели обучения имеют место определенные изменения уровня и структуры эмоционального интеллекта у современной молодежи. Также современные студенты обладают специфичными для нового поколения психологическими особенностями, которые могут быть взаимосвязаны с эмоциональным интеллектом. Однако на сегодняшний день в отечественной науке научных исследований по этому вопросу не представлено.

В исследовании Люсина и Овсянниковой (2015) возрастной разброс респондентов составил от 17 до 49 лет, что делает невозможным как сравнение результатов исследования с данными, полученными в 2006 г., так и рассмотрение изменений во взаимосвязи эмоционального интеллекта и личностных черт между представителями разных поколений.

Также следует отметить, что до сих пор ведутся дискуссии на тему целесообразности выделения эмоционального интеллекта как самодостаточного концепта, а не включения его в личностные черты. Например, концепция эмоционального интеллекта Носенко 
Дикая Л. А., Обухова Ю. В., Егорова В. А., Егоров И. Н.

ОСОБЕННОСТИ ВЗАИМОСВЯЗЕЙ ЭМОЦИОНАЛЬНОГО ИНТЕЛЛЕКТА И ЛИЧНОСТНЫХ ЧЕРТ...

РосСИЙСКИЙ пСИХОЛОГИЧЕСКИЙ ЖУРнАл, 2020, Т. 17, № 4, 34-48. doi: 10.21702/rpj.2020.4.3

психология личности

и Коврига (см. Андреева, 2009) рассматривает совокупность личностных черт как признак эмоционального интеллекта. В то же время Андреева (2009) выступает против включения эмоционального интеллекта в совокупность личностных черт.

В зарубежной литературе вопрос взаимосвязи эмоционального интеллекта и личностных черт представлен более обширно (Alghamdi, Aslam, \& Khan, 2017; Alegre, Pérez-Escoda, \& López-Cassá, 2019; Avsec et al., 2009; Hjalmarsson \& Dåderman, 2020; Edobor \& Joseph, 2020). Большинство исследовательских данных были положены в основание метааналитических статей, результаты которых носят противоречивый характер. Например, авторами одних исследований делается вывод о тождестве эмоционального интеллекта и GFP (General Factor of Personality) (Anglim, Morse, Dunlop, Minbashian, \& Marty, 2020; van der Linden et al., 2017). В другом метааналитическом исследовании корреляции между личностными чертами и эмоциональным интеллектом не обнаружены (Miao, Humphrey, Qian, \& Pollack, 2019). Следует также отметить, что все метааналитические исследования базировались преимущественно на разных моделях эмоционального интеллекта и личностных черт.

Таким образом, можно прийти к выводу, что имеющиеся на данный момент исследования носят противоречивый и неполный характер, т. к. большинство из них не были посвящены непосредственному изучению взаимосвязи эмоционального интеллекта и личностных черт, а те из них, что рассматривали данный вопрос, не могут быть сопоставимы по нескольким объективным причинам. Во-первых, исследователи опираются на различные теории и представления о личностных чертах. Во-вторых, существенным образом различаются выборки по возрастному составу. Соответственно, проследить изменения взаимосвязи эмоционального интеллекта и личностных черт, например, между различными поколениями, не представляется возможным. При этом возросшая в наши дни социальная активность молодых людей, требующая успешной межличностной коммуникации, регуляции эмоциональных состояний своих и собеседника, побуждает пересмотреть вопрос взаимосвязи эмоционального интеллекта и психологических характеристик современных студентов.

Таким образом, целью нашей работы являлось исследование взаимосвязей показателей эмоционального интеллекта и личностных черт у социально активных студентов.

В рамках исследования были выдвинуты следующие гипотезы:

1. У социально активных студентов могут быть выражены общие и специфичные взаимосвязи структурных компонентов эмоционального интеллекта с личностными чертами. Общие взаимосвязи будут характерны для всех компонентов эмоционального интеллекта, тогда как специфичные - для отдельных его компонентов.

2. Определенное сочетание личностных черт у социально активных студентов может влиять на выраженность у них эмоционального интеллекта.

\section{Методы}

Исследование проводилось в два этапа - предварительного и основного. Участниками предварительного этапа исследования выступили 197 студентов в возрасте от 17 до 25 лет, обучающихся в Южном федеральном университете (преимущественно социогуманитарных направлений подготовки) и принимающих участие в различных профессиональных, творческих конкурсах, студенческих проектных интенсивах, проектах социальной направленности, что было подтверждено официальными списками участников этих мероприятий. Участие студентов в исследовании было добровольным. На предварительном этапе исследования им 
Дикая Л. А., Обухова Ю. В., Егорова В. А., Егоров И. Н.

ОСОБЕННОСТИ ВЗАИМОСВЯЗЕЙ ЭМОЦИОНАЛЬНОГО ИНТЕЛЛЕКТА И ЛИЧНОСТНЫХ ЧЕРТ...

РосСиЙский психологИЧЕский ЖУРнАл, 2020, Т. 17, № 4, 34-48. doi: 10.21702/rpj.2020.4.3

психология личности

предлагалось заполнить анкету с демографическими данными и отметить уровень собственной социальной активности (низкий, средний, высокий, ниже или выше среднего).

На основном этапе исследования было предложено принять участие тем отобранным в результате анкетирования 150-ти студентам, которые по результатам самооценки собственной социальной активности отметили ее высокий уровень и уровень выше среднего. Следовательно, социальная активность студентов, принявших участие в исследовании, определялась объективным (участие в социальных мероприятиях) и субъективным (высокий и выше среднего уровень социальной активности) факторами, что соответствует представлениям о ее сущностных характеристиках - самодетерминированности и включенности во взаимодействие (Харланова, 2011).

Все предложенные задания основного этапа эмпирического исследования полностью выполнили 132 студента из 150-ти отобранных на предварительном этапе. Представленные в статье результаты получены при исследовании этих 132-х социально активных студентов (в возрасте от 17 до 25 лет): 80-ти женщин (средний возраст = $19 \pm 2)$ и 52-х мужчин (средний возраст = $21 \pm 3)$. Участникам основного этапа исследования предлагалось заполнить методики: опросник эмоционального интеллекта «ЭмИн» Д. В. Люсина (Люсин, 2006), «Big Five Inventory-2» («Вопросник Большой Пятерки-2») в русской адаптации С. А. Щебетенко (Shchebetenko, Kalugin, Mishkevich, Soto, \& John, 2018). Статистическая обработка данных проводилась при помощи программы R (Джеймс, Уиттон, Хасти и Тибширани, 2016) и включала в себя описательный анализ, корреляционный анализ по критерию Спирмена, множественный регрессионный анализ по критерию Стьюдента.

\section{Результаты и их обсуждение}

В таблицах 1 и 2 представлены результаты описательной статистики шкал эмоционального интеллекта и личностных черт социально активных студентов. Во всех признаках наблюдается нормальность распределения.

Следует отметить разброс средних значений показателей эмоционального интеллекта по выборке. На основе средних значений показателей эмоционального интеллекта по выборке студентов можно отметить средний уровень развития межличностного (44 балла) и общего (86 баллов) эмоционального интеллекта и низкий (37 баллов) уровень внутриличностного эмоционального интеллекта. При нормативных средних значениях межличностного (40-46 баллов), внутриличностного (39-47 баллов) и общего (79-92 балла) эмоционального интеллекта (Люсин, 2006) каждый из диагностируемых показателей эмоционального интеллекта у разных участников нашего исследования варьирует от очень низкого уровня до высокого (табл. 1, табл. 2).

В результате проведенного корреляционного анализа выявлены общие взаимосвязи структурных компонентов эмоционального интеллекта с различными показателями личностных черт (рис. 1). 
Дикая Л. А., Обухова Ю. В., Егорова В. А., Егоров И. Н.

ОСОБЕННОСТИ ВЗАИМОСВЯЗЕЙ ЭМОЦИОНАЛЬНОГО ИНТЕЛЛЕКТА И ЛИЧНОСТНЫХ ЧЕРТ...

РОсСиЙскИЙ ПСИХОЛОГИЧЕСКИЙ ЖУРНАЛ, 2020, Т. 17, № 4, 34-48. doi: 10.21702/rpj.2020.4.3

психология личности

\begin{tabular}{|c|c|c|c|c|}
\hline \multicolumn{5}{|c|}{$\begin{array}{l}\text { Таблица } 1 \\
\text { Описательные статистики шкал методики «ЭмИн» }\end{array}$} \\
\hline & \multicolumn{4}{|c|}{ Межличностный эмоциональный интеллект } \\
\hline & Понимание & Упр & ение & Межличностный \\
\hline & эмоций & & gми & эмоциональный интел^ект \\
\hline $\begin{array}{l}\text { Минимальное } \\
\text { значение }\end{array}$ & 14 & & & 26 \\
\hline Медиана & 24 & & & 43 \\
\hline Среднее & 25 & & & 44 \\
\hline Максимальное & 36 & & & 65 \\
\hline \multirow[t]{3}{*}{ SD } & 5 & & & 9 \\
\hline & \multicolumn{4}{|c|}{ Общий эмоциональный интемлект } \\
\hline & $\begin{array}{l}\text { Понимание } \\
\text { эмоций }\end{array}$ & \multicolumn{2}{|c|}{$\begin{array}{l}\text { Управление } \\
\text { эмоциями }\end{array}$} & $\begin{array}{c}\text { Общий эмоциональный } \\
\text { интелмект }\end{array}$ \\
\hline $\begin{array}{l}\text { Минимальное } \\
\text { значение }\end{array}$ & 23 & \multicolumn{2}{|c|}{17} & 52 \\
\hline Медиана & 42 & \multicolumn{2}{|c|}{39} & 84 \\
\hline Среднее & 43 & \multicolumn{2}{|c|}{40} & 86 \\
\hline Максимальное & 62 & \multicolumn{2}{|c|}{57} & 121 \\
\hline \multirow[t]{3}{*}{ SD } & 9 & \multicolumn{2}{|c|}{9} & 16 \\
\hline & \multicolumn{4}{|c|}{ Внутриличностный эмоциональный интел^ект } \\
\hline & $\begin{array}{l}\text { Понимание } \\
\text { эмоций }\end{array}$ & $\begin{array}{l}\text { Управление } \\
\text { эмоциями }\end{array}$ & $\begin{array}{c}\text { Контроль } \\
\text { экспрессии }\end{array}$ & $\begin{array}{c}\text { Внутриличностный } \\
\text { эмоциональный } \\
\text { интел^ект }\end{array}$ \\
\hline $\begin{array}{l}\text { Минимальное } \\
\text { значение }\end{array}$ & 10 & 4 & 0 & 10 \\
\hline Медиана & 18 & 13 & 10 & 39 \\
\hline Среднее & 19 & 13 & 11 & 37 \\
\hline Максимальное & 30 & 21 & 20 & 66 \\
\hline$S D$ & 5 & 4 & 4 & 14 \\
\hline
\end{tabular}


Дикая Л. А., Обухова Ю. В., Егорова В. А., Егоров И. Н.

ОСОБЕННОСТИ ВЗАИМОСВЯЗЕЙ ЭМОЦИОНАЛЬНОГО ИНТЕЛЛЕКТА И ЛИЧНОСТНЫХ ЧЕРТ..

РОссийский псиХологИчЕСКИй ЖУРнАл, 2020, Т. 17, № 4, 34-48. doi: 10.21702/rpj.2020.4.3

психология личности

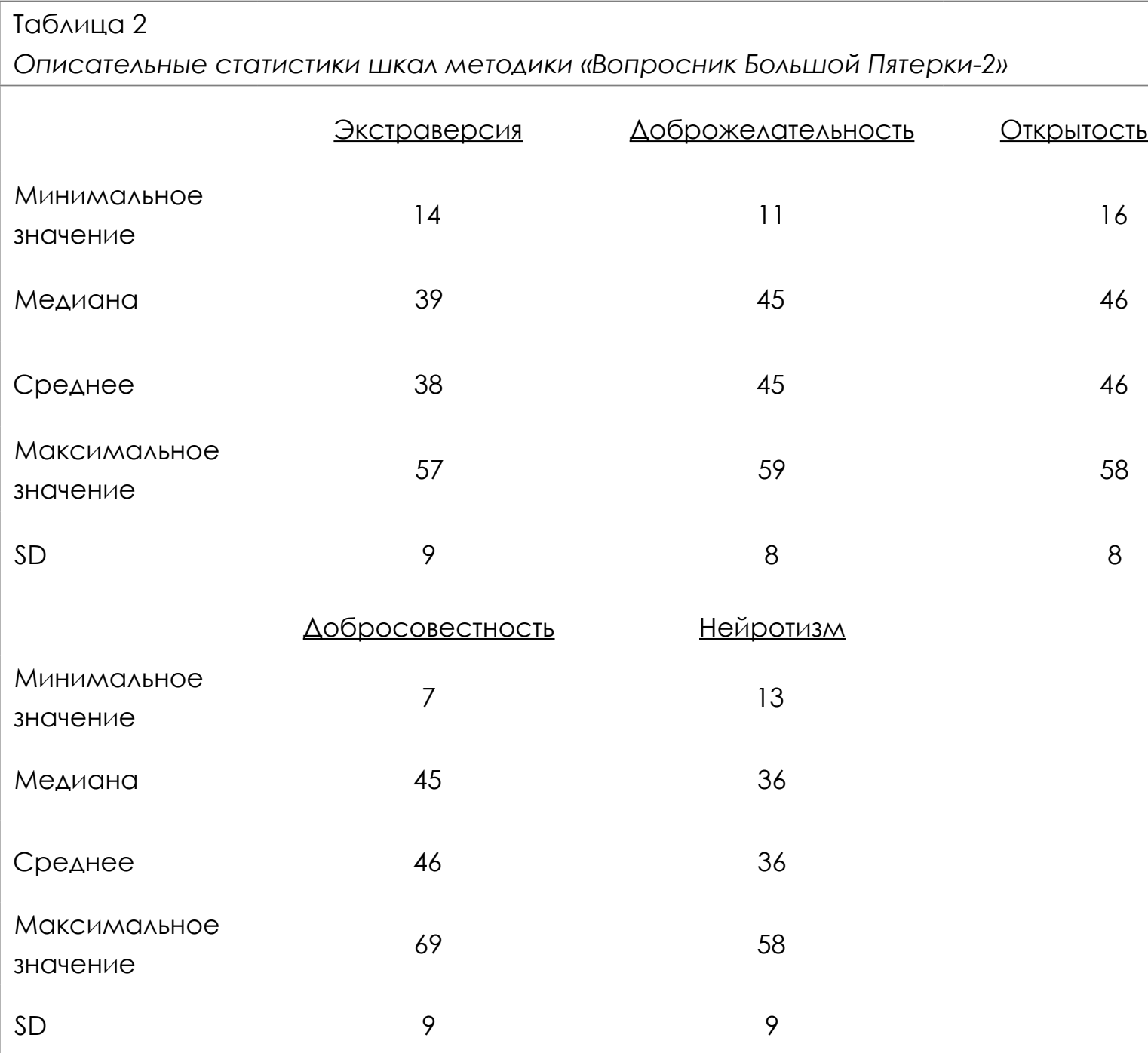

Обнаружена достоверная положительная корреляция между показателями шкалы «энергичность» (аспект фактора «экстраверсия») и шкал «управление чужими эмоциями» $(r=0,54$; $\mathrm{p}<0,01)$, «общий уровень межличностного эмоционального интеллекта» $(r=0,50$; $p<0,01)$, «общий уровень эмоционального интеллекта» $(r=0,51 ; p<0,01)$. Также выявлена достоверная отрицательная корреляция между шкалами: «управление своими эмоциями» и «депрессивность» (аспект фактора «нейротизм») ( $r=-0,51 ; p<0,01)$; «контроль экспрессии» и «нейротизм» $(r=-0,51 ; p<0,01)$; «общий уровень эмоционального интеллекта» и «нейротизм» $(r=-0,54 ; p<0,01)$; «общий уровень эмоционального интеллекта» и «тревожность» (аспект фактора «нейротизм») $(r=-0,50 ; p<0,01)$; «контроль экспрессии» и «эмоциональная изменчивость» (аспект фактора «нейротизм») $(r=-0,54 ; p<0,01)$; «общий уровень эмоционального интеллекта» и «эмоциональная изменчивость» (аспект фактора «нейротизм») $(r=-0,50 ; p<0,01)$. 
Дикая Л. А., Обухова Ю. В., Егорова В. А., Егоров И. Н.

ОСОБЕННОСТИ ВЗАИМОСВЯЗЕЙ ЭМОЦИОНАЛЬНОГО ИНТЕЛЛЕКТА И ЛИЧНОСТНЫХ ЧЕРТ...

РоссиЙскИй пСИХолОГИчЕСКИЙ ЖУРнАл, 2020, Т. 17, № 4, 34-48. doi: 10.21702/rpj.2020.4.3

психология личности

\begin{tabular}{|c|c|c|c|c|c|c|c|c|c|c|c|}
\hline \multicolumn{11}{|c|}{ Показатели эмоционального интемекта } & \\
\hline Аичностные черть & 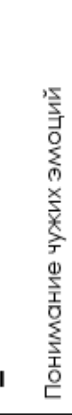 & 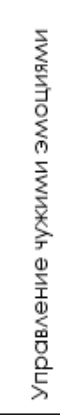 & 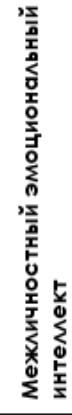 & 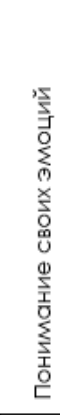 & 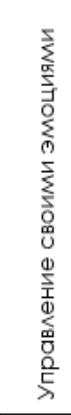 & 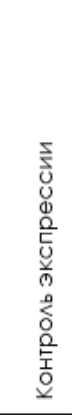 & 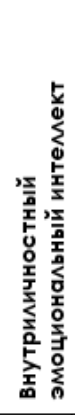 & 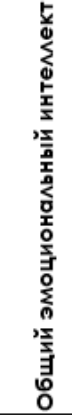 & 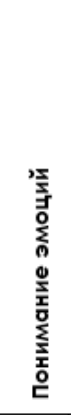 & 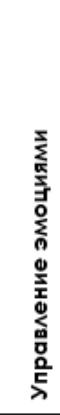 & \\
\hline Экстраверсия & 0,2 & 0,4 & 0,4 & $\theta+1$ & 0,3 & 0,2 & 0,3 & 0,4 & 0,2 & 0,4 & \\
\hline общительность & 0,1 & $\theta+1$ & 0,2 & 0,3 & 0,3 & $\theta$ & 0,1 & 0,2 & 0,2 & 0.2 & \\
\hline Ассертивность & 0,3 & 0,5 & 0,5 & 0.1 & 0,4 & 0,3 & 0,3 & 0,5 & 0,3 & 0,5 & \\
\hline Энергичность & 0,1 & 0,4 & 0,3 & 0,4 & 0,4 & 0,3 & 0,3 & 0,4 & 0.1 & 0,4 & \\
\hline Аоброжелательность & $\theta$ & 0,2 & 0,12 & $\theta$ & $\theta$ & 0,1 & 0,1 & 0,1 & $\theta$ & 0.1 & \\
\hline Сочувствие & 0,1 & 0,2 & 0,1 & $\theta$ & $\theta$ & $0+1$ & $\theta$ & 0,1 & $\theta$ & 0.2 & \\
\hline Уважительность & 0,2 & 0,2 & 0,2 & 0.1 & $\theta$ & 0,1 & 0,1 & 0,2 & $0+1$ & 0.2 & \\
\hline Аоверие & $\theta$ & $\theta$ & $\theta$ & $-0,1$ & $\theta$ & $\theta$ & $\theta$ & $\theta$ & $\theta+1$ & $\theta$ & \\
\hline АОбросовестность & $\theta$ & 0,2 & 0,1 & 0,1 & 0,3 & 0,2 & 0,3 & 0,2 & $0+1$ & 0,2 & \\
\hline Организованность & $\theta$ & $\theta$ & $\theta$ & $\theta$ & 0,2 & 0,2 & 0,2 & 0,1 & $\theta$ & 0,2 & \\
\hline ПроАуктивность & $\theta$ & 0,1 & $\theta$ & 0,1 & 0,2 & 0,1 & 0,2 & 0,1 & $\theta$ & 0.2 & \\
\hline Ответственность & 0,1 & 0,2 & 0,1 & 0,1 & 0.2 & 0,3 & 0,3 & 0,3 & $2+1$ & 0.2 & \\
\hline Нейротизм & 0,3 & $-0,3$ & $-0,4$ & $-0,4$ & $-0,6$ & $-0,5$ & $-0,6$ & $-0,6$ & $-0,4$ & $-0,4$ & \\
\hline Іревожность & $-0,3$ & $-0,4$ & $-0,4$ & $-0,3$ & $-0,5$ & $-0,5$ & $-0,5$ & $-0,6$ & $-0,3$ & $-0,3$ & \\
\hline$\triangle е$ епрессивность & $-0,2$ & $-0,3$ & $-0,3$ & $-0,4$ & $-0,5$ & -0.2 & $-0,5$ & $-0,5$ & $-0,4$ & $-0,3$ & \\
\hline$\frac{\text { Эмоциональная }}{\text { Изменчивость }}$ & $-0,2$ & $-0,1$ & $-2,2$ & $-0,3$ & $-0,4$ & $-0,6$ & $-0,5$ & $-0,5$ & $-0,3$ & $-0,3$ & \\
\hline Открытость опыту & $\theta$ & 0,2 & 0,1 & 0,2 & $\theta$ & 0.1 & 0,1 & 0,1 & $0+1$ & $\theta$ & \\
\hline Аюбознательность & 0,2 & 0,2 & 0,2 & 0,2 & 0.2 & 0,2 & 0,2 & 0,3 & 0,2 & 0,2 & \\
\hline Эстетичность & $-0,1$ & $-0,1$ & 0,1 & $\theta$ & $-0,1$ & $\theta$ & $\theta$ & $-0,1$ & $\theta$ & 0,2 & \\
\hline $\begin{array}{r}\text { Кичностная } \\
\text { креативность }\end{array}$ & 0,2 & 0,3 & 0,3 & 0,2 & 0.1 & 0.1 & 0,1 & 0.4 & 0,3 & 0.4 & \\
\hline
\end{tabular}

Рисунок 1. Корреляционная матрица, Аемонстрирующая взаимосвязь показателей эмоционального интемлекта и мичностных черт

Условные обозначения: 1. В корреляционной матрице представлены значения коэффициента корреляции показателей методики «ЭмИн» и методики «Big Five Inventory-2» («Вопросник Большой Пятерки-2») (по Спирмену). 2. Значения коэффициентов корреляции с уровнем достоверности менее 0,05 зачеркнуты горизонтальной линией. 3. Полужирным и обычным шрифтом без подчеркивания отмечены соответственно интегральные показатели и их составляющие по методике "ЭмИн". Полужирным и обычным шрифтом с подчеркиванием обозначены соответственно интегральные показатели личностных черт и их составляющие по методике "Big Five Inventory-2" ("Вопросник Большой Пятерки-2"). 
Дикая Л. А., Обухова Ю. В., Егорова В. А., Егоров И. Н.

ОСОБЕННОСТИ ВЗАИМОСВЯЗЕЙ ЭМОЦИОНАЛЬНОГО ИНТЕЛЛЕКТА И ЛИЧНОСТНЫХ ЧЕРТ...

РосСийский психологИЧЕский ЖУРнАл, 2020, Т. 17, № 4, 34-48. doi: 10.21702/rpj.2020.4.3

психология личности

Вышеприведенные статистические данные указывают на то, что участники исследования с высоким уровнем экстраверсии как личностной черты имеют высокий уровень межличностного эмоционального интеллекта, что является логичным и естественным для стороннего наблюдателя, т. к. именно у социально активных студентов выражена направленность вовне, в социум, что способствует формированию его навыков. И если человек получает больше удовольствия от общения с людьми и делает это чаще, то, соответственно, и навыки взаимодействия, понимания чужих эмоций будут развиты у него выше. Вторая часть данных указывает на то, что принявшие участие в исследовании социально активные студенты с низкой выраженностью аспектов фактора «нейротизм» и самого этого фактора обладают более высоким уровнем внутриличностного эмоционального интеллекта по всем его шкалам. Это тоже представляется весьма соответствующим реальности и теоретической логике, поскольку умения управлять своими эмоциями, понимать их и контролировать экспрессию будут положительно сказываться на умении человека справляться с негативными эмоциями.

Выявленная в нашем исследовании взаимосвязь между факторами «нейротизм» и «экстраверсия» может быть рассмотрена как механизм психокоррекционного воздействия, когда, например, развитие экстраверсии будет приводить к изменению уровня нейротизма. С учетом того, что экстраверсия, в свою очередь, достоверно положительно взаимосвязана с уровнем межличностного эмоционального интеллекта, а нейротизм достоверно отрицательно взаимосвязан с внутриличностным эмоциональным интеллектом, причем некоторые компоненты внутриличностного эмоционального интеллекта связаны с компонентами межличностного, мы получаем определенную «круговую корреляцию». Это означает, что воздействуя на один из вышеописанных критериев, мы можем получить изменение всех включенных в этот круг параметров. Выявленная закономерность имеет высокое прикладное значение в оптимизации образовательного процесса, в психолого-педагогическом сопровождении обучающихся с особыми образовательными потребностями, например, с ограниченными возможностями здоровья, с различного рода аддикциями, с одаренными учащимися, в развитии внутриличностного эмоционального интеллекта у социально активных студентов.

Также наряду с общими взаимосвязями были обнаружены и специфические, а именно (см. рис. 1): «общительность» (составляющая интегрального показателя «экстраверсия») и интегральный показатель «добросовестность» достоверно положительно взаимосвязаны с компонентом «управление своими эмоциями» $(r=0,3$ при $p<0,05)$, а составляющая показателя «ответственность» положительно коррелирует с «контролем экспрессии» $(r=0,3$ при $\mathrm{p}<0,05)$. «Любознательность» и «личностная креативность» (составляющие интегрального показателя «открытость новому») положительно взаимосвязаны с «общим эмоциональным интеллектом» $(r=0,3$ при $p<0,05)$.

Следовательно, способность вызывать у других людей те или иные эмоции, снижать интенсивность нежелательных эмоций, а также возможность манипулирования людьми тесно взаимосвязаны с тем, насколько в целом человек общителен, открыт, уверен в себе, инициативен, креативен, проявляет лидерские качества, энергичен и полон энтузиазма, а также умеет справляться со стрессом, быть расслабленным, не проявлять тревожность и напряжение.

Уверенность в себе, энергичность, энтузиазм также высоко взаимосвязаны с умением социально активных студентов контролировать свои эмоции. Негативно сказываются на способности управлять своими эмоциями и их внешними проявлениями тревожность, постоянная 
Дикая Л. А., Обухова Ю. В., Егорова В. А., Егоров И. Н.

ОСОБЕННОСТИ ВЗАИМОСВЯЗЕЙ ЭМОЦИОНАЛЬНОГО ИНТЕЛЛЕКТА И ЛИЧНОСТНЫХ ЧЕРТ...

РосСИЙСКИЙ пСИХОЛОГИЧЕСКИЙ ЖУРнАл, 2020, Т. 17, № 4, 34-48. doi: 10.21702/rpj.2020.4.3

психология личности

напряженность и беспокойство, склонность к депрессивности, неумение сохранять оптимистичный настрой после неудачи, эмоциональная нестабильность, перепады настроения. Но между тревожностью, постоянной напряженностью и беспокойством, с одной стороны, и умением распознавать свои эмоции, с другой, достоверных взаимосвязей не выявлено. Однако умение справляться с эмоциями и их экспрессивными проявлениями у участников исследования оказалось взаимосвязанным с ответственностью, стабильностью, умением доводить дела до их завершения, настойчивостью, организованностью, склонностью соблюдать порядок. При этом, чем выше у студентов развита способность распознавать и корректным образом интерпретировать свои эмоции, тем менее выражены у них склонность к депрессивности, неумение сохранять оптимистичный настрой после неудачи, эмоциональная нестабильность, перепады настроения.

Интересным фактом является различие результатов, полученных ранее и в нашем исследовании. Например, в нашем исследовании личностная черта «экстраверсия» положительно взаимосвязана со всеми интегральными структурными компонентами эмоционального интеллекта, за исключением «понимания эмоций», тогда как в исследовании Люсина и Овсянниковой (2015) она обладает достоверной взаимосвязью лишь с «межличностным эмоциональным интеллектом». В этом же исследовании личностная черта «добросовестность» положительно взаимосвязана со всеми интегральными структурными компонентами эмоционального интеллекта, тогда как в описанных выше результатах она связана лишь с «внутриличностным эмоциональным интеллектом»; личностная черта «доброжелательность» связана с «пониманием эмоций», «межличностным эмоциональным интеллектом» и «общим эмоциональным интеллектом», тогда как в полученных нами результатах достоверных взаимосвязей обнаружено не было. Возможно, результаты отличаются ввиду различного возрастного состава выборок, разных временных периодов проведения исследования и представленности в выборке нашего исследования социально активных студентов.

При проведении множественного регрессионного анализа было создано три модели, в основание которых легли три основных структурных компонента эмоционального интеллекта - «общий эмоциональный интеллект» (табл. 3), «межличностный эмоциональный интеллект» (табл. 4), «внутриличностный эмоциональный интеллект» (табл. 5). В каждой из моделей рассматривалось влияние выраженности личностных черт на данный компонент эмоционального интеллекта.

Рассмотрим результаты множественного регрессионного анализа относительного компонента «общий эмоциональный интеллект», который является интегральным по отношению к остальным в методике. Модель 1 отражает влияние интегральных показателей личностных черт на выраженность интегрального показателя «общий эмоциональный интеллект» на статистически значимом уровне ( $<<0,01)$, доля объясненной дисперсии составила 0,37, т. е. около $37 \%$ процентов данных эмоционального интеллекта могут быть объяснены при помощи совокупности личностных черт, включенных в данную модель. Исходя из данной модели, мы можем увидеть, что такие интегральные показатели личностных черт, как «экстраверсия», «нейротизм» и «доброжелательность», влияют на выраженность общего эмоционального интеллекта на статистически значимом уровне ( $<<0,05)$, а также существенную роль играет влияние факторов «нейротизм»и «доброжелательность» $(p<0,05)$ друг на друга (табл. 3). 
Дикая Л. А., Обухова Ю. В., Егорова В. А., Егоров И. Н.

ОСОБЕННОСТИ ВЗАИМОСВЯЗЕЙ ЭМОЦИОНАЛЬНОГО ИНТЕЛЛЕКТА И ЛИЧНОСТНЫХ ЧЕРТ...

РосСиЙский психологИЧЕский ЖУРнАл, 2020, Т. 17, № 4, 34-48. doi: 10.21702/rpj.2020.4.3

психология личности

Таблица 3

Молель 1 множественного регрессионного анализа

Молель 1. Общий эмоциональный инте^^ект

Коэфорициенты

Интегральный показатель

^ичностных черт

Экстраверсия

Нейротизм

Открытость новому опыту

Аоброжелательность

Взаимовлияние нейротизма

и Аоброжелательности

\author{
Стандартная \\ ошибка
}

0,23780

0,65043

0.22260

0,63540

0,01676 †-статистика

2,051

1,903

$-2,364$

2,214
Уровень

Аостоверности

0,044617 *

$0,000564^{* * *}$

$0,061816$.

$0,021341 *$

$0,030637 *$

R-квалрат: 0,4184; скорректированный R-кваАрат: 0,3699

F-статистика: 8,632; $p<0,001$

Уровни Аостоверности: 0 '***' 0,001 '**' 0,01 '*' 0,05 '.'

В модели 2 демонстрируется влияние интегральных показателей личностных черт на выраженность структурного компонента «межличностный эмоциональный интеллект» (доля объясненной дисперсии $18 \%$, р < 0,005). В этом случае «экстраверсия», «нейротизм» и «доброжелательность» достоверно влияют на выраженность «межличностного эмоционального интеллекта» ( $p<0,05)$. Также выявлено взаимовлияние факторов «нейротизм» и «доброжелательность» $(\mathrm{p}<0,05)$ (табл. 4).

В модели 3 рассматривается влияние интегральных показателей личностных черт на структурный компонент «внутриличностный эмоциональный интеллект» (доля объясненной дисперсии составила 0,39 при р < 0,001), т. е. $39 \%$ показателей эмоционального интеллекта обусловлены влиянием личностных черт. Исходя из данной модели, можно заключить, что на внутриличностный эмоциональный интеллект достоверно влияют такие личностные черты, как «экстраверсия», «нейротизм», «добросовестность». Также выявлено достоверное взаимовлияние факторов «экстраверсия» и «нейротизм» $(p<0,01)$ (табл. 5). 
Дикая Л. А., Обухова Ю. В., Егорова В. А., Егоров И. Н.

ОСОБЕННОСТИ ВЗАИМОСВЯЗЕЙ ЭМОЦИОНАЛЬНОГО ИНТЕЛЛЕКТА И ЛИЧНОСТНЫХ ЧЕРТ...

РосСИЙСКИЙ пСИХОЛОГИЧЕСКИЙ ЖУРнАл, 2020, Т. 17, № 4, 34-48. doi: 10.21702/rpj.2020.4.3

психология личности

\begin{tabular}{|c|c|c|c|}
\hline \multicolumn{4}{|c|}{ МоАель 2. Межличностный эмоциональный интеллект } \\
\hline \multicolumn{4}{|l|}{ Коэфорициенты } \\
\hline $\begin{array}{l}\text { Интегральный показатель } \\
\text { ^ичностных черт }\end{array}$ & $\begin{array}{l}\text { Стандартная } \\
\text { ошибка }\end{array}$ & †-статистика & $\begin{array}{c}\text { Уровень } \\
\text { Аостоверности }\end{array}$ \\
\hline Экстраверсия & 0,14678 & 2,832 & $0,00625 * *$ \\
\hline Нейротизм & 0,38385 & $-2,705$ & $0,00885 * *$ \\
\hline Аоброжелательность & 0,36830 & $-2,050$ & $0,04468 *$ \\
\hline Аобросовестность & 0,127652 & $-0,072$ & 0,94312 \\
\hline $\begin{array}{l}\text { Взаимовлияние нейротизма } \\
\text { и ооброжелательности }\end{array}$ & 0,01001 & 2,186 & $0,03267^{*}$ \\
\hline \multicolumn{4}{|c|}{$\begin{array}{c}\text { R-квалрат: 0,2341; скорректированный R-квалрат: 0,1839 } \\
\text { F-статистика: 4,661; p }<0,01\end{array}$} \\
\hline
\end{tabular}

\section{Таблица 5}

Молель 3 множественного регрессионного анализа

Молель 3. Внутриличностный эмоциональный интелмект

Коэфорициенты

Интегральный показатель

Аичностных черт

Стандартная ошибка

Экстраверсия

Нейротизм

Открытость новому опыту

Аоброжелательность

Взаимовлияние нейротизма

и экстраверсии

Аобросовестность

$\begin{array}{ll}0,63156 & -2,673 \\ 0,61641 & -4,025 \\ 0,18736 & 0,963 \\ 0,21037 & -0,687 \\ 0,01662 & 2,732 \\ 0,18742 & 3,228\end{array}$

Уровень Аостоверности

$0,009695^{* *}$

$0,000165^{* * *}$

0,339284

0,494628

$0,008296 * *$

$0,002040 * *$ 
Дикая Л. А., Обухова Ю. В., Егорова В. А., Егоров И. Н.

ОСОБЕННОСТИ ВЗАИМОСВЯЗЕЙ ЭМОЦИОНАЛЬНОГО ИНТЕЛЛЕКТА И ЛИЧНОСТНЫХ ЧЕРТ...

РосСиЙский психологИЧЕский ЖУРнАл, 2020, Т. 17, № 4, 34-48. doi: 10.21702/rpj.2020.4.3

психология личности

Однако согласно данным, полученным исследователями на выборке из Саудовской Аравии, «нейротизм» и «добросовестность» не влияют на выраженность эмоционального интеллекта (Аленези, 2020). Тогда как в нашем исследовании при помощи множественного регрессионного анализа было выявлено значимое влияние «нейротизма» на все структурные компоненты эмоционального интеллекта, хотя данные о влиянии «экстраверсии» и «доброжелательности» согласуются с результатами исследования Аленези (2020). Эти различия в результатах могут быть обусловлены этнокультурными особенностями выборки. В то же время ряд других исследований подтверждает взаимосвязь эмоционального интеллекта и личностной черты «нейротизм» на достоверном уровне (Люсин и Овсянникова, 2015), а также влияние всех личностных черт на выраженность эмоционального интеллекта (Alegre et al., 2019). Значимое влияние «нейротизма» и «экстраверсии» для обоих полов также отмечается в исследовании, проведенном на англоязычной выборке (Siegling, Furnham, \& Petrides, 2015).

\section{Заключение}

На основе обобщения результатов проведенного эмпирического исследования сделаны следующие выводы:

1. Показано, что у социально активных студентов выражены общие, характерные для всех компонентов, и специфичные, характерные для отдельных компонентов эмоционального интеллекта, его взаимосвязи с личностными чертами. К общим отнесены взаимосвязи интегрального показателя «нейротизм», а также его составляющей «тревожность» со всеми структурными компонентами эмоционального интеллекта. К специфичным отнесены положительные взаимосвязями показателя «энергичность» (составляющей интегрального показателя «экстраверсия») со структурными компонентами эмоционального интеллекта, отвечающими за управление эмоциями, а также отрицательные взаимосвязи показателя «эмоциональная лабильность» (составляющей интегрального показателя «нейротизм») со структурными компонентами внутриличностного эмоционального интеллекта ( $p \leq 0,05)$.

2. Выявлено, что на выраженность эмоционального интеллекта у социально активных студентов оказывают влияние как отдельные интегральные личностные черты, так и их сочетания. Сочетание нейротизма и доброжелательности влияет на выраженность общего и межличностного эмоционального интеллекта, а сочетание экстраверсии и нейротизма - на выраженность внутриличностного эмоционального интеллекта.

Полученные в исследовании результаты и сделанные на их основе выводы подтверждают гипотезы исследования и могут получить применение при разработке рекомендаций по психолого-педагогическому сопровождению студентов с особыми образовательными потребностями в социальной активности, с лидерской одаренностью. Выявленные закономерности могут быть взяты за основу при разработке педагогических технологий, тренинговых программ, индивидуальных образовательных траекторий студентов.

\section{Благодарности}

Исследование выполнено при финансовой поддержке Южного федерального университета, 2020, № ВнГр-07/2020-02-АП.

\section{Литература}

Аленези, А. М. (2020). Взаимосвязь эмоционального интеллекта студентов и уровня их готовности к онлайн-образованию: контекстуальное исследование на примере 
Дикая Л. А., Обухова Ю. В., Егорова В. А., Егоров И. Н.

ОСОБЕННОСТИ ВЗАИМОСВЯЗЕЙ ЭМОЦИОНАЛЬНОГО ИНТЕЛЛЕКТА И ЛИЧНОСТНЫХ ЧЕРТ...

РосСИЙСКИЙ пСИХОЛОГИЧЕСКИЙ ЖУРнАл, 2020, Т. 17, № 4, 34-48. doi: 10.21702/rpj.2020.4.3

психология личности

университетского обучения в Саудовской Аравии. Образование и наука, 22(4), 89-109. doi: 10.17853/1994-5639-2020-4-89-109

Андреева, И. Н. (2009). Концептуальное поле понятия «эмоциональный интеллект». Вопросы психологии, 4, 131-141.

Белоконь, О. В. (2008). Эмоциональный интеллект и феномен лидерства: эксперимент «Строим вместе». Психология. Журнал высшей школы экономики, 5(3), 137-144.

Бочкова, М. Н. и Мешкова, Н. В. (2018). Эмоциональный интеллект и социальное взаимодействие: зарубежные исследования. Современная зарубежная психология, 7(2), 49-59. doi: 10.17759/jmfp.2018070205

Воробьева, Е. В., Перков, М. А. и Щетинина, Д. П. (2017). Исследование взаимосвязи принятия агрессии и эмоционального интеллекта. Российский психологический журнал, 14(2), $28-50$. doi: 10.21702/rpj.2017.2.2

Джеймс, Г., Уиттон, Д., Хасти, Т. и Тибширани, Р. (2016). Введение в статистическое обучение с примерами на языке R. Москва: ДМК Пресс.

Краснов, Е. В. (2018). Эмоциональный интеллект в личностной регуляции принятия решений (кандидатская диссертация). Московский государственный университет имени М. В. Ломоносова, Москва.

Люсин, Д. В. (2004). Современные представления об эмоциональном интеллекте. В Д. В. Люсин, Д. В. Ушаков (ред.), Социальный интеллект: Теория, измерение, исследования (с. 29-36). Москва: Институт психологии РАН.

Люсин, Д. В. (2006). Новая методика для измерения эмоционального интеллекта: опросник ЭмИн. Психологическая диагностика, 4, 3-22.

Люсин, Д. В. и Овсянникова, В. В. (2015). Связь эмоционального интеллекта и личностных черт с настроением. Психология. Журнал Высшей школы экономики, 12(4), 154-164. doi: 10.17323/1813-8918-2015-4-154-164

Обухова, Ю. В. (2013). Интеллектуальные особенности представителей социономических и несоциономических профессий в период ранней взрослости. Северо-Кавказский психологический вестник, 11/2, 59-62.

Обухова, Ю. В. и Обухова, С. Г. (2015). Особенности характеристик и смыслообразующих мотивов самореализации студенческой молодежи. Российский психологический журнал, 12(4), 21-30. doi: 10.21702/rpj.2015.4.2

Харланова, Е. М. (2011). Социальная активность студентов: сущность понятия. Теория и практика общественного развития, 4, 183-186.

Шипитько, О. Ю. (2019). Взаимосвязь эмоционального интеллекта и совладающего поведения военнослужащих. В А. Н. Гуда, Е. С. Сипко, Н. В. Луговая, В. В. Смеюха (ред.), Реклама и связи с общественностью: традиции и инновации (с. 223-228). Ростов-на-Дону: Ростовский государственный университет путей сообщения.

Alegre, A., Pérez-Escoda, N., \& López-Cassá, E. (2019). The relationship between trait emotional intelligence and personality. Is trait El really anchored within the Big Five, Big Two and Big One frameworks? Frontiers in Psychology, 10, 866. doi: 10.3389/fpsyg. 2019.00866

Alghamdi, N. G., Aslam, M., \& Khan, K. (2017). Personality traits as predictor of emotional intelligence among the university teachers as advisors. Education Research International, 1-6. doi: 10.1155/2017/9282565

Anglim, J., Morse, G., Dunlop, P. D., Minbashian, A., \& Marty, A. (2020). Predicting trait emotional intelligence from HEXACO personality: Domains, facets, and the general factor of personality. 
Дикая Л. А., Обухова Ю. В., Егорова В. А., Егоров И. Н.

ОСОБЕННОСТИ ВЗАИМОСВЯЗЕЙ ЭМОЦИОНАЛЬНОГО ИНТЕЛЛЕКТА И ЛИЧНОСТНЫХ ЧЕРТ...

РосСиЙский психологИЧЕский ЖУРнАл, 2020, Т. 17, № 4, 34-48. doi: 10.21702/rpj.2020.4.3

психология личности

Journal of Personality, 88(2), 324-338. doi: 10.1111/jopy.12493

Atta, M., Ather, M., \& Bano, M. (2013). Emotional intelligence and personality traits among university teachers: Relationship and gender differences. International Journal of Business and Social Science, 4(17), 253-259.

Avsec, A., Takšić, V., \& Mohorić, T. (2009). The relationship of trait emotional intelligence with the Big Five in Croatian and Slovene university student samples. Psihološka Obzorja / Horizons of Psychology, 18(3), 99-110.

Edobor, O. J., \& Joseph, O. I. (2020). Personality traits and birth order as correlate of emotional intelligence among secondary school students in Delta State. KIU Journal of Social Sciences, 6(1), 137-144.

Haight, R. C., Kolar, C., Nelson, M. H., Fierke, K. K., Sucher, B. J., \& Janke, K. K. (2017). Assessing emotionally intelligent leadership in pharmacy students. American Journal of Pharmaceutical Education, 81(2), 29. doi: 10.5688/ajpe81229

Hjalmarsson, A. K. V., \& Dåderman, A. M. (2020). Relationship between emotional intelligence, personality, and self-perceived individual work performance: A cross-sectional study on the Swedish version of TEIQue-SF. Current Psychology. doi: 10.1007/s12144-020-00753-w

Lyusin, D., \& Mohammed, A.-R. (2018). Are emotionally intelligent people more emotionally stable? An experience sampling study. Higher School of Economics Research Paper, WP BRP 88/ PSY/2018. doi: $10.2139 /$ ssrn.3110738

Megías-Robles, A., Gutiérrez-Cobo, M. J., Gómez-Leal, R., Cabello, R., Gross, J. J., \& FernándezBerrocal, P. (2019). Emotionally intelligent people reappraise rather than suppress their emotions. PloS One, 14(8), e0220688. doi: 10.1371/journal.pone.0220688

Miao, C., Humphrey, R. H., Qian, S., \& Pollack, J. M. (2019). The relationship between emotional intelligence and the dark triad personality traits: A meta-analytic review. Journal of Research in Personality, 78, 189-197. doi: 10.1016/j.jrp.2018.12.004

Saakyan, O. S. (2015). Electrophysiological analysis of the cognitive component of social creativity in young males and females with different individual characteristics. Psychology in Russia: State of the Art, 8(4), 83-90. doi: 10.11621/pir.2015.0407

Salovey, P., \& Mayer, J. D. (1990). Emotional intelligence. Imagination, Cognition and Personality, 9(3), 185-211. doi: 10.2190/DUGG-P24E-52WK-6CDG

Shchebetenko, S., Kalugin, A. Y., Mishkevich, A. M., Soto, C. J., \& John, O. P. (2018). Russian version of The Big Five Inventory-2 / Русская версия вопросника Big Five Inventory-2. Personality Measurement. doi: 10.13140/RG.2.2.16022.65608

Siegling, A. B., Furnham, A., \& Petrides, K. V. (2015). Trait emotional intelligence and personality: Gender-invariant linkages across different measures of the Big Five. Journal of Psychoeducational Assessment, 33(1), 57-67. doi: 10.1177/0734282914550385

Stolarski, M., Jankowski, K. S., Matthews, G., \& Kawalerczyk, J. (2016). Wise "birds" follow their clock: The role of emotional intelligence and morningness-eveningness in diurnal regulation of mood. Chronobiology International, 33(1), 51-63. doi: 10.3109/07420528.2015.1115413

van der Linden, D., Pekaar, K. A., Bakker, A. B., Schermer, J. A., Vernon, P. A., Dunkel, C. S., \& Petrides, K. V. (2017). Overlap between the general factor of personality and emotional intelligence: A meta-analysis. Psychological Bulletin, 143(1), 36-52. doi: $10.1037 /$ bul0000078

van der Zee, K., Thijs, M., \& Schakel, L. (2002). The relationship of emotional intelligence with academic intelligence and the Big Five. European Journal of Personality, 16(2), 103-125. doi: 10.1002/per.434

Конфликт интересов отсутствует 